\title{
Aryl substitution of pentacenes
}

\author{
Andreas R. Waterloo ${ }^{1}$, Anna-Chiara Sale ${ }^{1}$, Dan Lehnherr ${ }^{2}$, Frank Hampel ${ }^{1}$ \\ and Rik R. Tykwinski ${ }^{* 1}$
}

\author{
Full Research Paper \\ Address: \\ ${ }^{1}$ Department of Chemistry and Pharmacy \& Interdisciplinary Center \\ for Molecular Materials (ICMM), University of Erlangen-Nürnberg \\ (FAU), Henkestrasse 42, 91054 Erlangen, Germany and ${ }^{2}$ Department \\ of Chemistry, University of Alberta, Edmonton, AB T6G 2G2, Canada \\ Email: \\ Rik R. Tykwinski* - rik.tykwinski@fau.de \\ * Corresponding author \\ Keywords: \\ carbon-nanomaterials; organic semiconductor; pentacene; m-stacking; \\ polycyclic aromatic hydrocarbon; solid-state structure
}

Beilstein J. Org. Chem. 2014, 10, 1692-1705. doi:10.3762/bjoc. 10.178

Received: 06 February 2014

Accepted: 25 June 2014

Published: 28 July 2014

This article is part of the Thematic Series "Functionalized carbon-nanomaterials".

Guest Editor: A. Krueger

(C) 2014 Waterloo et al; licensee Beilstein-Institut. License and terms: see end of document.

\begin{abstract}
A series of 11 new pentacene derivatives has been synthesized, with unsymmetrical substitution based on a trialkylsilylethynyl group at the 6-position and various aryl groups appended to the 13-position. The electronic and physical properties of the new pentacene chromophores have been analyzed by UV-vis spectroscopy (solution and thin films), thermoanalytical methods (DSC and TGA), cyclic voltammetry, as well as X-ray crystallography (for 8 derivatives). X-ray crystallography has been specifically used to study the influence of unsymmetrical substitution on the solid-state packing of the pentacene derivatives. The obtained results add to our ability to better predict substitution patterns that might be helpful for designing new semiconductors for use in solid-state devices.
\end{abstract}

\section{Introduction}

Conjugated organic molecules are promising candidates for use in optoelectronic applications including OLEDs [1], photovoltaics [2], and OFETs [3]. Even though there is literally an infinite number of possibilities to chemically assemble small organic molecules for such applications, clever design and synthesis have rapidly offered new materials for the nascent era of molecular electronic [4-11]. Prominent p-type organic semiconductors include substituted acenes in general [12-15], and specifically 6,13-(triisopropylsilylethynyl)pentacene (TIPSPc) $[13,14]$. The latter was synthesized by Anthony over a decade ago [16], but it is still a leading focus of the scientific commu-

nity. Substituted pentacenes can offer several advantages to other small molecule semiconductors, including stability, processability, and semiconductor device performance. Intermolecular $\pi-\pi$-interactions between chromophores can be dramatically improved upon functionalization at the 6- and 13-positions of pentacene, as demonstrated by the two-dimensional (2D) bricklayer-packing motif for TIPSPc [13,14]. A number of well-designed substitution patterns for the pentacene skeleton have been realized to date [17-25], and pentacene derivatives that provide good semiconductor device performance often show similar 6,13-substitution patterns (Figure 1a) 
$[12,26]$. The most reactive positions of the acene core are the 6and 13-positions [27-29], and these positions can be effectively blocked by different trialkylsilylethynyl units [30]. Inspired by previous studies in which we [18,31], and others [32-34], observed promising solid-state arrangement and properties of aryl-substituted pentacenes, we were interested in the influence of different aryl moieties directly linked to the pentacene core. In this work we present a simple synthetic approach to unsymmetrically substituted pentacenes via stepwise functionalization of pentacenequinone, using a nucleophilic aryl group (Figure 1b). To determine the influence of aryl substitution, the obtained pentacenes have been studied by a variety of spectroscopic characterization methods as well as X-ray crystallography of eight derivatives. The studies reported herein offer an opportunity to interpret various properties of acenes based on their substitution and should contribute toward the use of such derivatives in materials science.

\section{Results and Discussion Synthesis and Characterization Synthesis}

The synthesis of arylpentacenes was developed based on the known ketone derivatives $\mathbf{4 a}$ and $\mathbf{4 b}$, formed through the addition of an acetylide to pentacenequinone (Scheme 1) [21,35-38]. With these two ketones in hand, a second nucleophilic addition was initiated. Thus, commercially available aryl halides dissolved in dry THF were subjected to lithium halogen exchange at $-78{ }^{\circ} \mathrm{C}$ using $n$-butyllithium. A substoichiometric amount of $n$-BuLi was used in each case to ensure complete consumption of the $n$-BuLi through Li-halogen exchange and thus avoid the possibility of competitive addition of the nucleophilic $n$-Bu anion to the ketone group of either $\mathbf{4 a}$ or $\mathbf{4 b}$. After reaction with the appropriate aryl lithium species, the reaction was quenched with a proton source, and the resulting diol intermediates $\mathbf{5} \mathbf{a}-\mathbf{h}$ were carried on directly to reductive aromatiza- tion with $\mathrm{SnCl}_{2} / \mathrm{H}_{2} \mathrm{SO}_{4}$ without further purification, ultimately yielding pentacene products $\mathbf{3 a}-\mathbf{h}$. While the isolation and characterization of diol products resulting from nucleophilic additions to pentacenequinone has been possible [17,18,34], previous work has shown that aromatized products were more easily purified by column chromatography and recrystallization following the last step $[30,31,36]$. Thus, it was deemed procedurally more efficient to eliminate the purification step of the intermediate diols. Once formed, pentacenes $\mathbf{3 a}-\mathbf{h}$ were obtained in moderate yield over two steps, as deep-blue solids.

To expand the $\pi$-system in a linear fashion along the short molecular axis of the pentacene core, the general procedure described above was changed slightly, and ketone 4a was treated with a solution of biphenylmagnesium bromide in THF. After work-up and isolation of the intermediate diol $\mathbf{5 i}$, reductive aromatization gave pentacene $\mathbf{3 i}$ in moderate yield over the two steps. Elaborating on the general idea of lateral functionalization, iodoaryl pentacene $\mathbf{3 g}$ offered an opportunity to vary the pendent substituent through a Pd-catalyzed cross-coupling protocol (Scheme 2). Thus, pentacene $\mathbf{3 g}$ was treated under Suzuki-Miyaura coupling conditions with arylboronic acids, and the desired pentacenes $\mathbf{3} \mathbf{j}, \mathbf{k}$ were obtained in yields of 92 and $68 \%$, respectively. Notably, anthracenyl-substituted pentacene $3 \mathbf{k}$ was the least stable of all derivatives synthesized in this study. It slowly decomposed in solution when exposed to ambient laboratory conditions and was unstable toward silica gel chromatography. Compound 3k could, however, be purified by recrystallization from a mixture of $\mathrm{MeOH}$ and acetone.

\section{UV-vis spectroscopy}

Aryl pentacenes $\mathbf{3 a}-\mathbf{k}$ have been studied by $\mathrm{UV}-$ vis absorption spectroscopy in $\mathrm{CH}_{2} \mathrm{Cl}_{2}$ solutions and as thin films cast from $\mathrm{CH}_{2} \mathrm{Cl}_{2}$ onto quartz. Solution-state $\mathrm{UV}-$ vis spectra show char- a)<smiles>[R15][SiH2]C#Cc1c2cc3ccccc3cc2c(C#C[AsH])c2cc3ccccc3cc12</smiles>

$1 \mathrm{R}=$ alkyl, aryl, etc. TIPSPc $\mathrm{R}=\mathrm{iPr}$ previous work

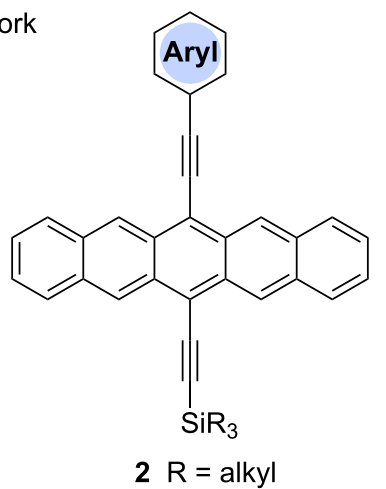

b)

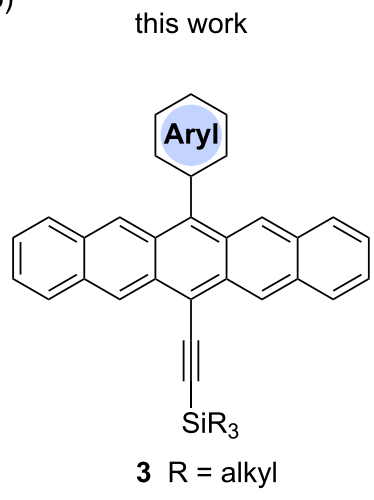

Figure 1: a) Examples of common pentacene functionalization patterns and b) unsymmetrically aryl-substituted pentacenes reported in this work. 
<smiles>[R3][SiH2]C#CC1(O)c2cc3ccccc3cc2C(=O)c2cc3ccccc3cc21</smiles>

4b $\mathrm{R}=\mathrm{Et}$
1. Aryl-M $\mathrm{M}=\mathrm{Li}$ or $\mathrm{MgBr}$ $\stackrel{\text { THF, rt 16-18 h }}{\longrightarrow}$ 2. $\mathrm{NH}_{4} \mathrm{Cl}, \mathrm{H}_{2} \mathrm{O}$

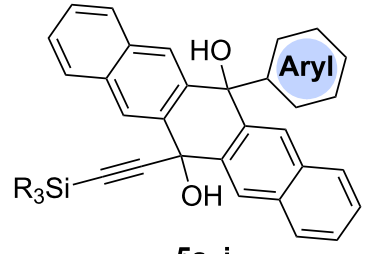

5a-i

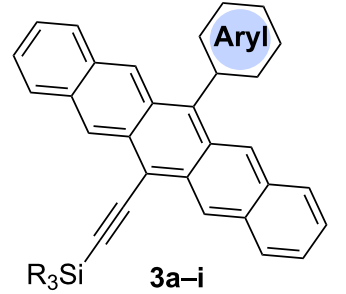

$\mathrm{rt}, 6 \mathrm{~h}$

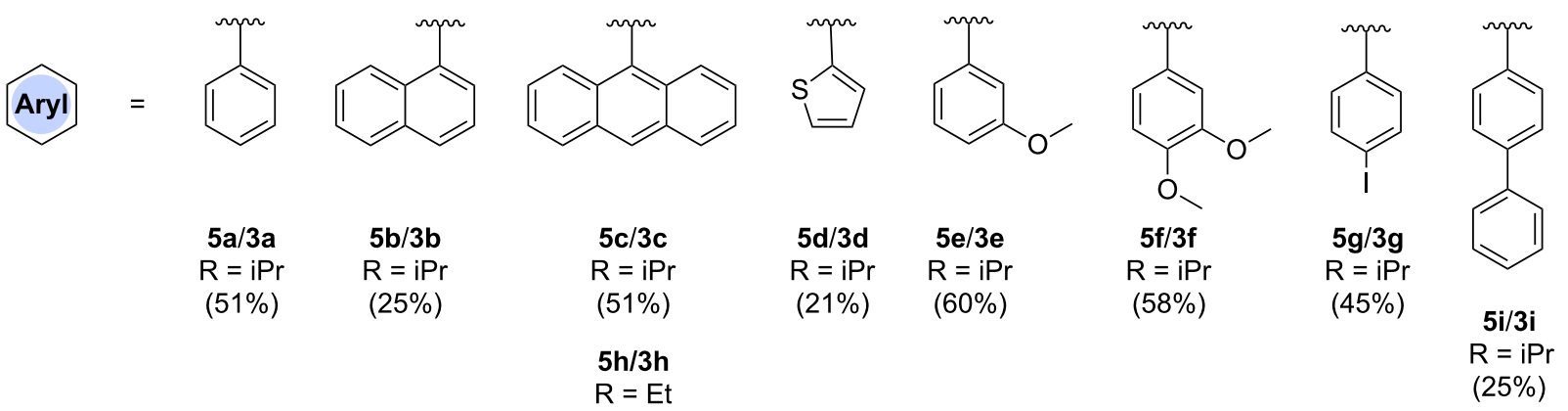

$(8 \%)$

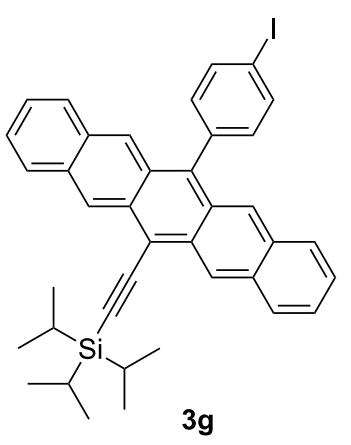

Aryl-B(OH)
$\mathrm{Pd}(\mathrm{PPh})_{2} \mathrm{Cl}_{2}, \mathrm{Na}_{2} \mathrm{CO}_{3}$

THF, reflux,

2-4 h

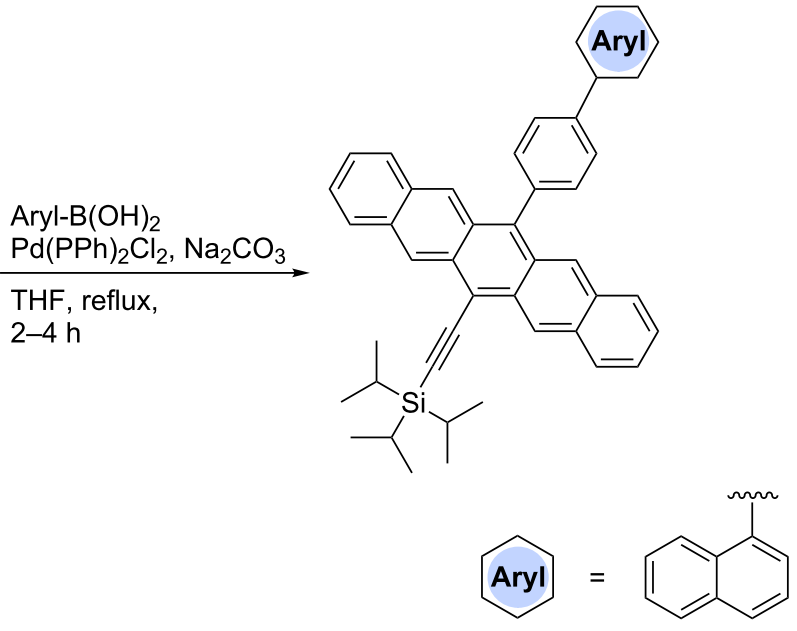

3j (92\%)

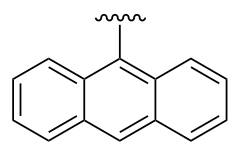

3k $(68 \%)$

Scheme 2: Functionalization of iodoaryl pentacene $\mathbf{3 g}$ using the Suzuki-Miyaura cross-coupling reaction.

acteristic absorptions in the high-energy region with a maximum intensity absorption centered at $\sim 310 \mathrm{~nm}$, as well as low-energy absorptions at $\sim 578 \mathrm{~nm}$ and $\sim 622 \mathrm{~nm}$. In comparison, unsubstituted pentacene $(\mathrm{PEN})$ shows a $\lambda_{\max }=576 \mathrm{~nm}$ (measured in benzene) [39], while the symmetrically substituted analogue TIPSPc shows a low-energy absorption at $643 \mathrm{~nm}$ (measured in $\mathrm{CH}_{2} \mathrm{Cl}_{2}$ ) due to extended conjugation through the two alkyne substituents [11].
As can be seen in the representative spectra in Figure 2, the nature and size of aryl substituents at the 13-position does not alter the basic absorption wavelengths as one progresses, for example, through the series of phenyl (3a), naphthyl (3b) and anthracenyl (3c), although some differences in molar absorptivity are observed. Similar trends are observed within the series of pentacenes $\mathbf{3 i}, \mathbf{3} \mathbf{j}$, and $\mathbf{3 k}$. Thus, these UV-vis spectra clearly document the lack of communication between the aryl 
substituent and the pentacene unit, as a result of hindered rotation about the aryl-pentacene $\mathrm{C}-\mathrm{C}$ bond and a preferred conformation in which the $\pi$-system of the aryl group is orthogonal to that of the pentacene. The orthogonal orientation of the aryl groups is also well-documented in the solid state by X-ray crystallographic analysis (vide infra). The fluorescence characteristics of 3a-k are unremarkable, showing only minor variances in emission wavelength ranging from $652-671 \mathrm{~nm}$, as measured in $\mathrm{CH}_{2} \mathrm{Cl}_{2}$ (see Supporting Information File 1 for details and spectra).

a)

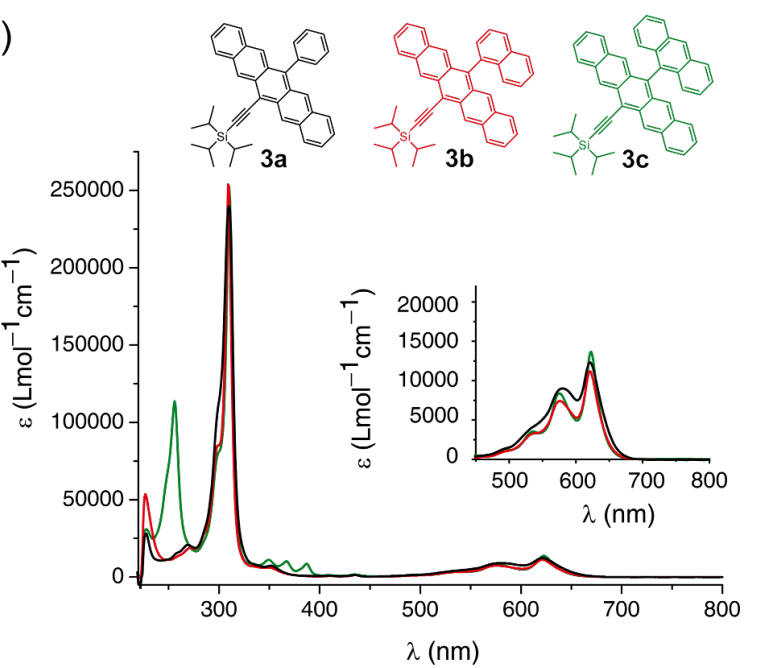

b)

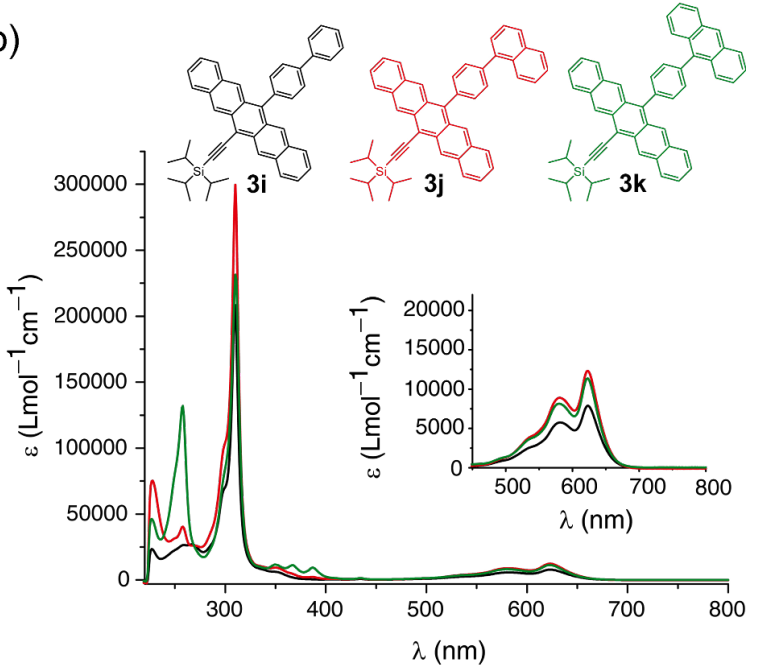

Figure 2: UV-vis spectra of pentacenes a) $\mathbf{3 a - c}$ and b) $\mathbf{3 i - k}$ (measured in $\mathrm{CH}_{2} \mathrm{Cl}_{2}$ ).

The major electronic absorptions found in solution are also reproduced to a large extent in spectra obtained from solid-state films. Pentacene samples 3a-k were drop-cast from a concentrated $\mathrm{CH}_{2} \mathrm{Cl}_{2}$ solution onto a quartz surface, and after airdrying, the absorption spectra were measured by UV-vis spectroscopy (Figure 3 and Table 1). While this method sometimes results in rather significant scattering versus the formation of films by spin-casting, only milligram quantities of material are required and the results are qualitatively informative (i.e., absorption wavelengths can be readily discerned, while determination of molar absorptivity is not possible). As can be seen in Figure 3, spectra from thin films show absorption profiles similar to those from solution-state measurements, although signals are broadened and absorptivities vary dramatically due to scattering. In the solid state, there are no observed absorptions at wavelengths beyond ca. $660 \mathrm{~nm}$, and absorptions in the lower energy region show a red shift ( 7 to $33 \mathrm{~nm}$ ) in comparison to analogous absorptions in solution. A red shift in the absorption features of samples in the solid state relative to those in solution is typically ascribed to a local electronic interaction

a)
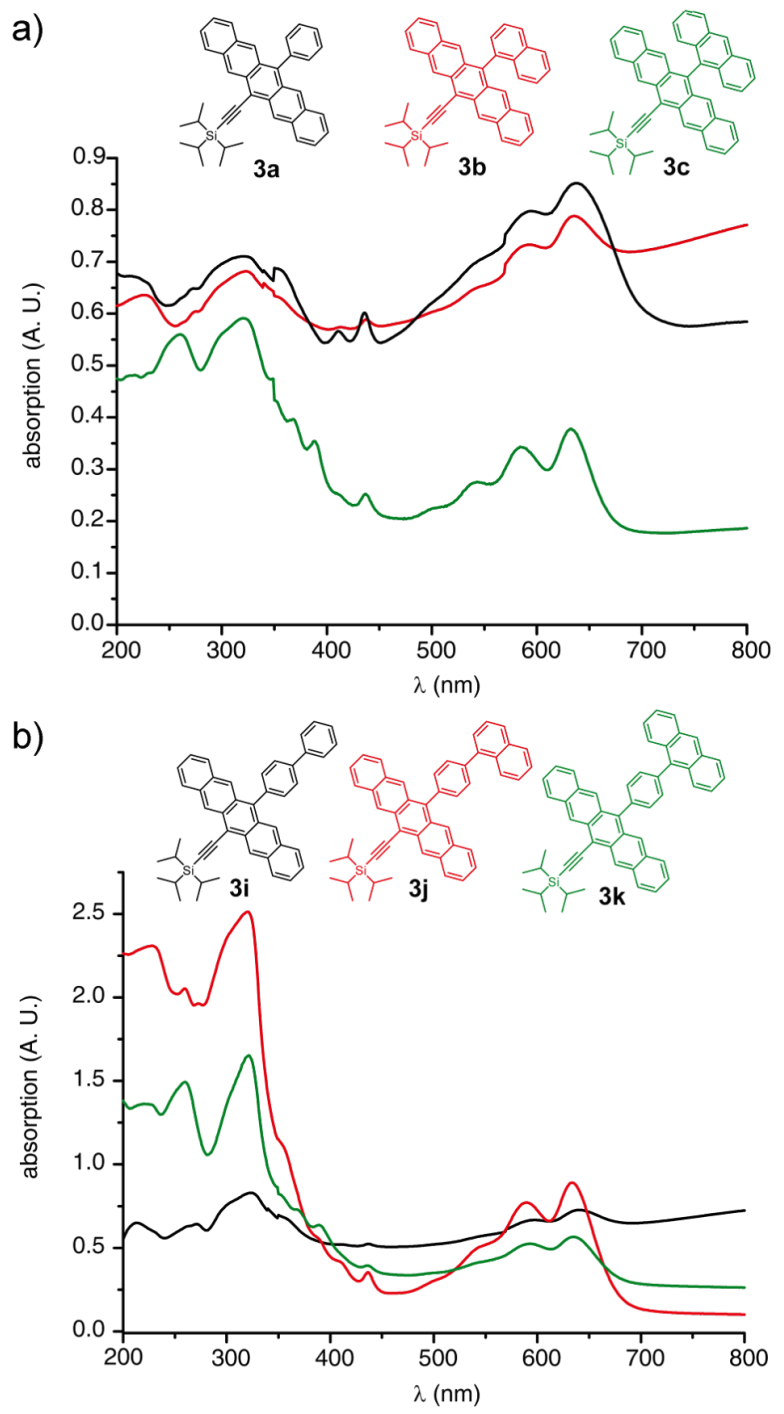

Figure 3: UV-vis spectra of thin films (drop cast on quartz from a $\mathrm{CH}_{2} \mathrm{Cl}_{2}$ solution) for pentacenes a) $3 \mathbf{a}-\mathbf{c}$ and b) $\mathbf{3 i}-\mathbf{k}$. 
Table 1: Optical properties of pentacenes 3a-k, unsubstituted pentacene (PEN), and TIPSPC.

\begin{tabular}{lllll} 
Compound & $\lambda_{\max }\left(\mathrm{in} \mathrm{CH}_{2} \mathrm{Cl}_{2}\right)^{\mathrm{a}}[\mathrm{nm}]$ & $\lambda_{\max }(\mathrm{film})^{\mathrm{b}}[\mathrm{nm}]$ & $E_{\mathrm{gap}, o p t}[\mathrm{eV}]^{\mathrm{c}}$ \\
\hline 3a & 621 & 637 & $16(50)$ & 1.89 \\
3b & 621 & 635 & $14(44)$ & 1.91 \\
3c & 623 & 637 & $14(44)$ & 1.92 \\
3d & 623 & 637 & $13(41)$ & 1.91 \\
3e & 621 & 634 & $33(100)$ & 1.89 \\
3f & 622 & 655 & $7(22)$ & 1.87 \\
3g & 621 & 628 & $16(50)$ & 1.90 \\
3h & 622 & 638 & $10(56)$ & 1.91 \\
3i & 623 & 641 & $12(38)$ \\
3j & 623 & 633 & $97(310)$ \\
3k & 623 & 635 & $62(170)$ \\
PEN & $576^{\mathrm{d}}$ & $673^{\mathrm{e}}$ & 1.88 \\
TIPSPc & $643^{\mathrm{f}}$ & $705^{\mathrm{g}}$ & 1.89 \\
\hline
\end{tabular}

aLowest energy absorption maxima. ${ }^{b} \mathrm{Cast}$ from $\mathrm{CH}_{2} \mathrm{Cl}_{2}$ onto quartz. ${ }^{\mathrm{c}}$ Determined from solution-state spectra, based on a tangent line applied to the lower edge of the longest wavelength absorption peak and the intercept with the x-axis. ${ }^{\mathrm{d}}$ Measured in benzene and data taken from [39]. ${ }^{\mathrm{e}} \mathrm{Data}$ taken from [41,42]. fData taken from [11]. 9Data taken from [35].

between the respective pentacene molecules in the solid state. Of the aryl pentacenes studied here, veratrole derivative $\mathbf{3 f}$ shows the largest red shift $(33 \mathrm{~nm})$ as a film compared to its solution-state UV-vis spectrum, although the origin of change in the solid state is not understood. It is worth noting, however, that more significant red-shifted $\lambda_{\max }$-values are often observed for samples which give solution cast films that result in significant $\pi$-stacking between molecules, such as TIPSPc, in which $\lambda_{\max }$ shifts from $643 \mathrm{~nm}$ in solution to ca. $705 \mathrm{~nm}$ in the solid film $[11,35,40]$. This same logic also suggests that the minimal difference between the absorption characteristics of $\mathbf{3 c}$ and $\mathbf{3 h}$ results from both a lack of influence from the different silyl groups, as well as the absence of strong $\pi$-stacking for both derivatives in the films, even though X-ray crystallographic analysis suggests that strong interactions might be possible for some derivatives in the solid state (vide infra).

\section{Thermal analysis}

The thermal stability of selected aryl pentacenes has been explored by traditional melting point analysis (MPA) in open capillary tubes, thermal gravimetric analysis (TGA), and differential scanning calorimetry (DSC) measurements; the results are summarized in Table 2. TGA shows clearly that significant mass loss occurs in the range of $400{ }^{\circ} \mathrm{C}$, which is also common

Table 2: Thermal properties of a representative selection of pentacenes.

\begin{tabular}{|c|c|c|c|c|c|}
\hline Compound & $\mathrm{R}$ & Aryl & $\begin{array}{l}\mathrm{TGA} T_{\mathrm{d}} \\
/^{\circ} \mathrm{C}^{\mathrm{a}}\end{array}$ & $\begin{array}{l}\text { MPA } \\
\mathrm{mp} /{ }^{\circ} \mathrm{C}^{\mathrm{b}}\end{array}$ & $\begin{array}{l}\text { DSC mp } \\
(\mathrm{DSC} d p) /{ }^{\circ} \mathrm{C}^{\mathrm{c}}\end{array}$ \\
\hline $3 a$ & $\mathrm{iPr}$ & & 370 & $162-165$ & $\begin{array}{l}177 \\
(178 / 179)\end{array}$ \\
\hline $3 b$ & iPr & & 370 & $244-246$ & 248 \\
\hline
\end{tabular}


Table 2: Thermal properties of a representative selection of pentacenes. (continued)

3d $3 \mathbf{3 i}$

${ }^{a}$ Measured under a nitrogen atmosphere. $T_{\mathrm{d}}=$ decomposition temperature, see Supporting Information File 1 for details. ${ }^{b}$ Traditional open capillary melting point analysis (MPA), measured under ambient conditions; uncorrected. ${ }^{c}$ Measured under a nitrogen atmosphere; dp = decomposition point, shown as onset/peak temperatures. dDecomposition observed in that temperature range, with no indication of melting or decomposition at lower temperature. ${ }^{e}$ Endotherm, although apparently not a true $\mathrm{mp}$ based on traditional $\mathrm{mp}$ analysis. Exotherm at $286^{\circ} \mathrm{C}$ (peak) likely corresponds to dp in DSC. ' The strongest of several endotherms.

for ethynylated pentacenes such as $\mathbf{1}$ and $\mathbf{2}$ [17,18]. There appears to be little evidence of a trend based on the size of the aryl group versus the temperature of observed mass loss in the TGA. By comparing the TGA data with that of MPA made in open capillary tubes, however, it is clear that all pentacene derivatives undergo either a phase change or decomposition prior to the mass loss observed in the TGA. This premise is also confirmed by DSC analyses, which show a melting point in all cases except for thienyl derivative 3d (which decomposed directly in the solid state). In the case of $\mathbf{3 a}$ and $\mathbf{3 h}$, melting is followed immediately by decomposition (DSC and TGA scans are provided in Supporting Information File 1).

While no correlation between pendent substituent and stability emerges from this analysis, an important point is nevertheless noted, as exemplified by the examination of $\mathbf{3 c}$ and $\mathbf{3 d}$. Traditional MPA is often insufficient for characterization of pentacene derivatives, in which subtle changes in the samples can be difficult to discern because of the deep, dark color of the sample, and conflicting results are often observed between MPA and DSC.

\section{Cyclic voltammetry}

Electrochemical analysis by cyclic voltammetry (CV) was used to investigate the electronic properties of pentacene derivatives 3a-k in $\mathrm{CH}_{2} \mathrm{Cl}_{2}$ (ca. $1.5 \mathrm{mM}$ ) using tetrabutylammonium hexafluorophosphate as supporting electrolyte and ferrocene as internal standard (all potentials reported are thus given versus
$\mathrm{Fc} / \mathrm{Fc}^{+}$). Aryl-substituted pentacenes $3 \mathbf{a}-\mathbf{k}$ each show a oneelectron reversible oxidation event in the range between $0.30-0.37 \mathrm{~V}$ (Table 3 ), and a second oxidation process (quasireversible) in the range of $0.80-0.99 \mathrm{~V}$. There is, unfortunately, no clear trend observed for the oxidation potentials based on the substitution pattern of the aryl moieties, although both oxidations appear somewhat easier for pentacene $\mathbf{3 f}$ as a result of the two electron-donating methoxy groups attached to the pendent phenyl ring.

Aryl-substituted pentacenes $\mathbf{3 a}-\mathbf{k}$ each show one reversible reduction event in a rather narrow range of -1.59 to $-1.68 \mathrm{~V}$. Similar to that observed for the oxidation potentials, there is no obvious trend that can be identified in the reduction potentials based on substitution pattern, aside from the observation that the silyl substituent might have a slight impact on reduction ( $3 \mathbf{h}$ is slightly harder to reduce than $\mathbf{3 c}$ ), and the reduction of thienyl derivative $3 \mathbf{d}(-1.59 \mathrm{~V})$ stands out as lower than the others.

Substituted pentacenes $\mathbf{3 a}-\mathbf{k}$ are slightly easier to oxidize than $\operatorname{TIPSPc}\left(E_{\mathrm{Ox} 1}=0.39 \mathrm{~V}\right)$, and the $E_{\mathrm{ox} 1}$ values of $\mathbf{3 a}-\mathbf{k}$ fall into a similar range as found for pentacene-based PAH dyads $\mathbf{2 a - c}$ in which the pendant aryl groups are linked by an ethynyl spacer that allows electronic communication between the two arenes [18]. The range of oxidation potentials between TIPSPc, $\mathbf{2} \mathbf{a}-\mathbf{c}$, and $\mathbf{3 a}-\mathbf{k}$ is, however, quite narrow, suggesting that the pendent substituent offers little influence on the HOMO level. On the other hand, there is a marked difference in the observed reduc- 
Table 3: Electrochemical properties of $\mathbf{3} \mathbf{a}-\mathbf{k}$ compared to TIPSPc and $\mathbf{2 a -} \mathbf{a} .^{\text {a }}$

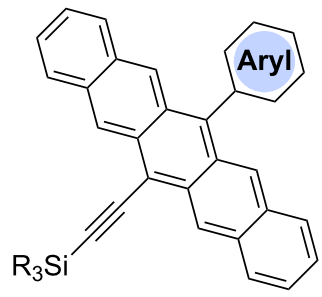

\begin{tabular}{lllllll}
\hline Compound & $\mathrm{R}$ & Aryl & $E_{\text {ox1 }}[\mathrm{V}]$ & $E_{\text {ox2 } 2}[\mathrm{~V}]$ & $E_{\text {red1 }}[\mathrm{V}]$ & $E_{\text {gap,el }}[\mathrm{eV}]^{\mathrm{b}}$ \\
3a & $\mathrm{iPr}$ & 0.34 & 0.87 & -1.63 & 1.97
\end{tabular}

$3 b$

$\mathrm{iPr}$

$3 c$

$\mathrm{iPr}$

$3 h$

Et

3d

$3 e$

iPr

iPr<smiles>Cc1cccc2ccccc12</smiles><smiles>CC(C)c1c2ccccc2cc2ccccc12</smiles>

0.36<smiles>CC(C)c1c2ccccc2cc2ccccc12</smiles>

0.32

0.35

0.32

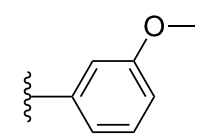

iPr

$3 f$

$3 g$

$3 i$

3j

$\mathrm{iPr}$

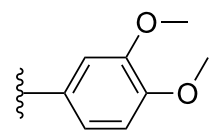

0.30

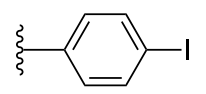

0.34

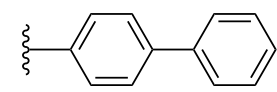

0.32

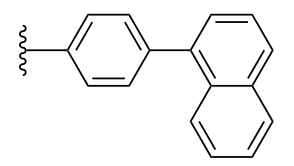

0.32

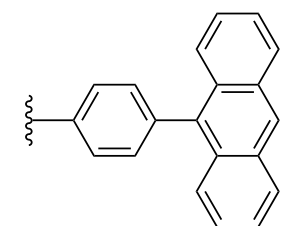

0.35

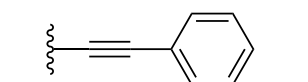

3k
iPr

$\mathrm{iPr}$

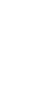

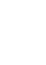

0.39
0.99

$-1.61$

1.98

0.93

$-1.65$

2.01

0.91

$-1.68$

2.00

0.87

0.87

$-1.68$

2.00

0.80

0.87

0.87

0.93

$-1.67$

1.99

0.88

$-1.67$

2.02 


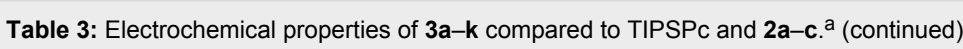

\begin{tabular}{|c|c|c|c|c|c|c|c|}
\hline $2 b^{c}$ & $\mathrm{iPr}$ & $\zeta$ & 1 & 0.39 & - & -1.42 & 1.81 \\
\hline $2 c^{c}$ & $\mathrm{iPr}$ & $\xi=$ & \rangle & 0.33 & - & -1.38 & 1.71 \\
\hline TIPSPc & iPr & $\xi=$ & $-\mathrm{Si}(\mathrm{iPr})_{3}$ & 0.39 & 0.99 & -1.52 & 1.91 \\
\hline
\end{tabular}

tion potentials. Compounds $\mathbf{2 a - c}$ are most easily reduced while $\mathbf{3 a}-\mathbf{k}$ are the most difficult, and the reduction of TIPSPc falls at approximately a midpoint between the two other classes. Thus, the biggest influence of the pendent substituent appears to be related to the energy of the LUMO.

As suggested by the UV-vis analyses (vide infra), the HOMO-LUMO gap estimated for pentacenes $\mathbf{3 a}-\mathbf{k}$ by CV $(1.94-2.02 \mathrm{eV})$ is larger than the HOMO-LUMO gap of TIPSPc $(1.91 \mathrm{eV})$, while incorporation of the ethynyl spacer in 2a-c provides for the lowest HOMO-LUMO gap of the molecules discussed here.

\section{X-ray crystallographic analysis}

Typically, three predominant solid-state packing patterns are found by X-ray crystallographic analysis of pentacene and its derivatives [13]: a) a herringbone packing, b) a one-dimensional (1D) slipped-stack, and c) a 2D "bricklayer" packing, as schematically summarized in Figure 4 . While several polymorphs have been reported for unsubstituted pentacene [43-46], the arrangement in the solid state is commonly the edge-to-face, herringbone motif [47]. This packing arrangement provides strong electronic coupling in the solid state, and therefore makes this material interesting as the active component for semiconducting devices [48]. It has been shown that functionalization of the pentacene framework, particular by trialkylsilylethynyl groups, drastically alters the solid-state arrangements of the acenes [30]. In certain cases, this leads to a 2D face-to-face "bricklayer" arrangement, which can potentially facilitate charge transport in an electric device by several orders of magnitude [49].

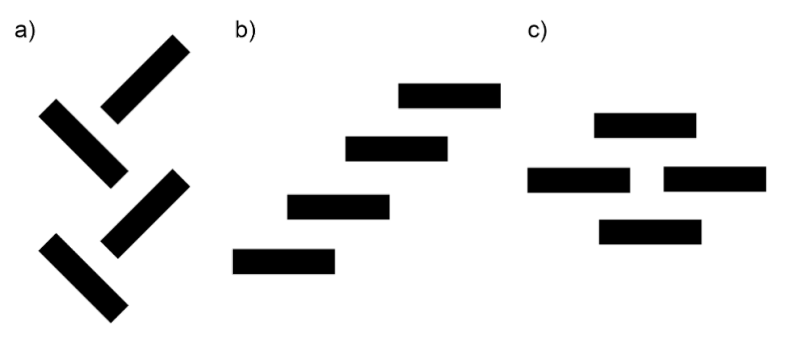

Figure 4: Schematic classification of three common solid-state arrangements of pentacene derivatives a) herringbone packing, b) 1D slipped-stack packing, and c) 2D "bricklayer" packing (as viewed sideon, approximately down the short-molecular axis).

With the understanding that the solid-state packing of acenes can provide vital information about intermolecular interactions, single crystals of pentacenes $\mathbf{3} \mathbf{a}-\mathbf{d}$ and $\mathbf{3} \mathbf{g}-\mathbf{j}$ were grown and their solid-state arrangements determined by single crystal $\mathrm{X}$-ray diffraction analysis (crystallographic details are provided in Supporting Information File 1). Pentacene 3a crystallizes in the space group $C 2 / c$ with eight molecules in the unit cell (Figure 5). Within the solid-state structure, the pendant phenyl ring and the pentacene core are slightly twisted, with a torsion angle of $\sim 71^{\circ}$. Molecules of pentacene 3a arrange as dimeric pairs, which then pack into a so-called sandwich herringbone motif (Figure 5c) [50]. Each dimeric pair of pentacenes shows face-to-face $\pi$-stacking interactions with an interplanar distance of $\sim 3.40 \AA$ and a total overlap of nearly four of the aromatic pentacene rings.

Pentacene $\mathbf{3 b}$ crystallizes in the space group $P-1$ with two molecules in the unit cell (Figure 6). Notably, the naphthyl unit is 


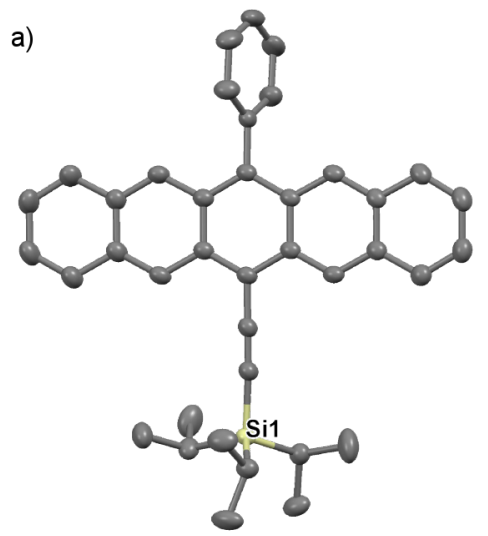

b)

Figure 5: X-ray crystallographic analysis of 3a showing a) molecular structure and b) packing motif (triisopropylsilyl groups omitted for clarity); ORTEP drawn at $50 \%$ probability level. c) Schematic representation of "sandwich herringbone" packing arrangement.

significantly disordered over two unique positions in the solid state but is nearly perpendicular to the pentacene core with a twist angle of $\sim 81^{\circ}$. Pentacene $\mathbf{3 b}$ assembles in dimeric pairs, which then arrange in a $1 \mathrm{D} \pi$-slipped stack motif, and the pentacene molecules are separated by interplanar distances of $\sim 3.42 \AA$ and $\sim 3.52 \AA$.

Pentacene $3 \mathbf{c}$ crystallizes in the space group $P 2_{1} / c$ with four molecules in the unit cell (Figure 7) [31]. The pentacene skeleton and the anthracenyl substituent are nearly perpendicular to each other with a twist angle of $\sim 90^{\circ}$. This motif also places the anthracene moieties in a face-to-face packing 1D slipped stack arrangement, although the interplanar distance of $\sim 3.61 \AA$ is sizable. The aromatic pentacene cores pack in a faceto-face $2 \mathrm{D}$ bricklayer arrangement, with approximately two pentacene rings overlapping and interplanar distances of $\sim 3.52 \AA$ and $3.46 \AA$.

Pentacene 3d crystallizes in the space group $P 2_{1} / n$ with four molecules in each unit cell (Figure 8), and the thienyl and trialkylsilyl groups show disorder in the structure. With a twist angle of $\sim 90^{\circ}$, the thienyl unit is essentially perpendicular to the pentacene skeleton. Centrosymmetric dimeric pairs of pentacene 3d pack with an interplanar distance of $3.52 \AA$ and these pairs then arrange into a sandwich herringbone stacking pattern, similar to phenyl derivative $\mathbf{3 a}$.

Pentacene $\mathbf{3 g}$ crystallizes in the space group $P 2_{1} / n$ with four molecules in the unit cell (Figure 9). The phenyl substituent is twisted with an angle of $\sim 70^{\circ}$ relative to the pentacene skeleton. a)

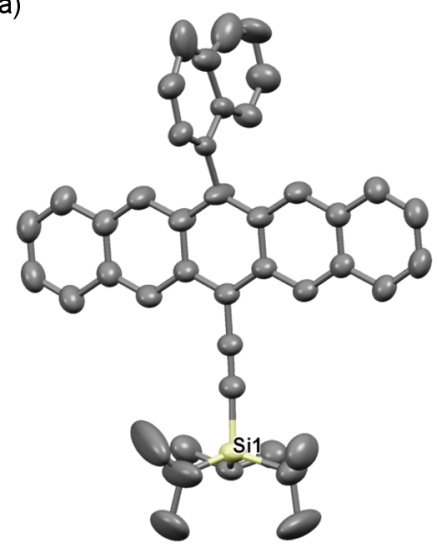

b)

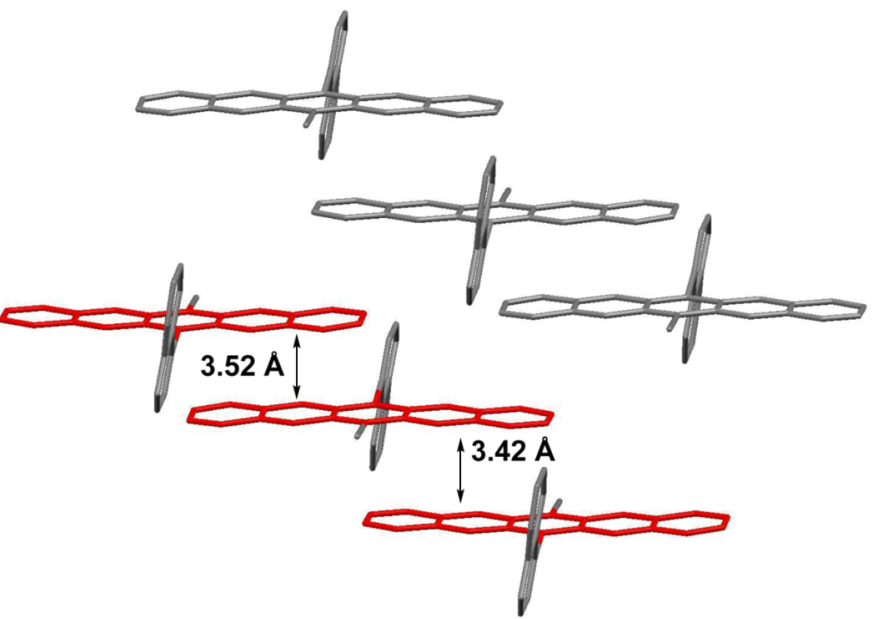

Figure 6: X-ray crystallographic analysis of $3 \mathbf{b}$ showing a) molecular structure and b) packing motif (triisopropylsilyl groups omitted for clarity); ORTEP drawn at $50 \%$ probability level. 
a)

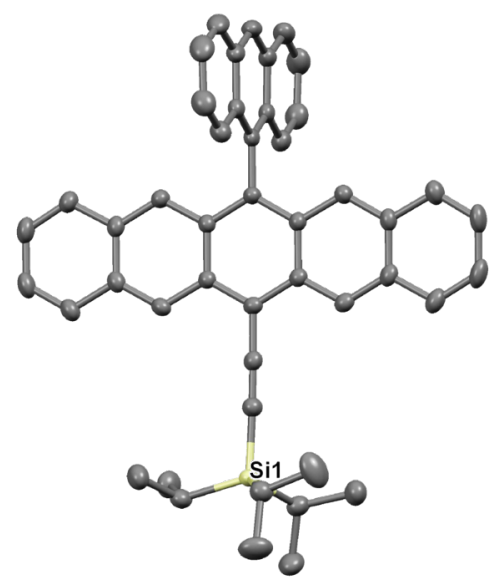

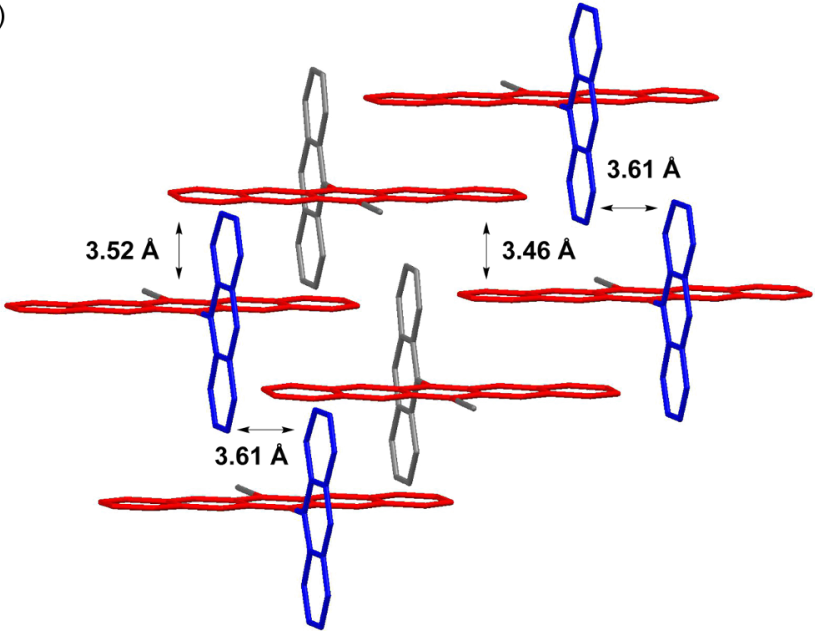

Figure 7: X-ray crystallographic analysis of $3 c$ showing a) molecular structure and b) packing motif (triisopropylsilyl groups omitted for clarity); ORTEP drawn at $50 \%$ probability level.

a)

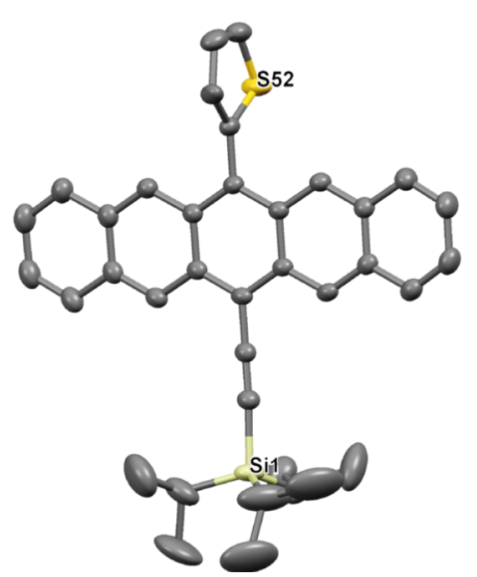

b)

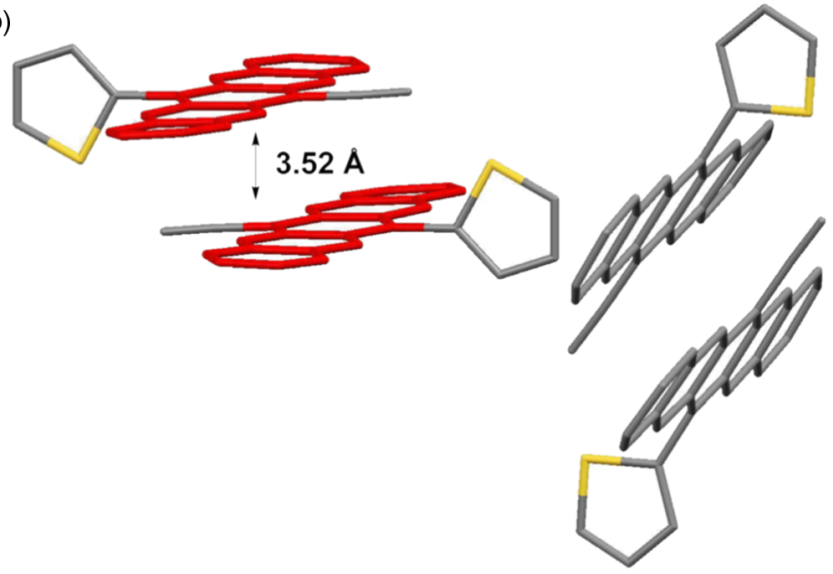

Figure 8: X-ray crystallographic analysis of $\mathbf{3 d}$ showing a) molecular structure, and b) packing motif (triisopropylsilyl groups omitted for clarity); ORTEP drawn at $50 \%$ probability level.

Two neighboring molecules of $\mathbf{3 g}$ arrange into a dimeric pair with an interplanar distance of $3.42 \AA$, and these pairs then pack in a sandwich herringbone arrangement. The overall solid-state arrangement is similar to that observed for $\mathbf{3 a}$ and $\mathbf{3 d}$.

Pentacene $\mathbf{3 h}$ crystallizes in the space group $P 2_{1} / c$ with four molecules in each unit cell (Figure 10). The anthracenyl substituent is twisted relative to the pentacene skeleton with an angle of $\sim 74^{\circ}$, less than that found for $3 \mathbf{c}\left(90^{\circ}\right)$. Interestingly, pentacene $3 \mathbf{h}$ shows an unusual solid-state arrangement not typically observed for pentacene derivatives. Namely, the pentacene molecules form channels along the crystallographic $a$-axis, which are composed of only two tiers of a brick wall structure. The pentacene molecules within these channels are stacked with an interplanar distance of $3.57 \AA$. These channels are macroscopically arranged as staircases, dictated by the anthracenyl moieties that are oriented such that $\mathrm{CH}-\pi$ interactions of $\sim 2.90 \AA$ likely play a role in directing the packing (see Supporting Information File 1, Figure S12).

Pentacene 3i crystallizes in the space group $P-1$ with two molecules in each unit cell (Figure 11). The benzene ring directly at- 
a)

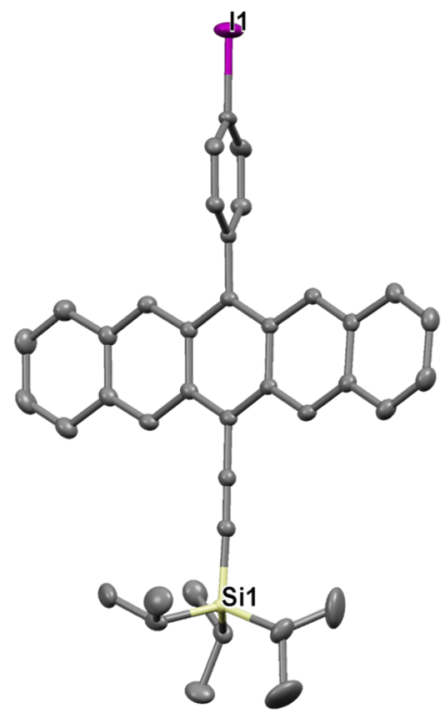

b)

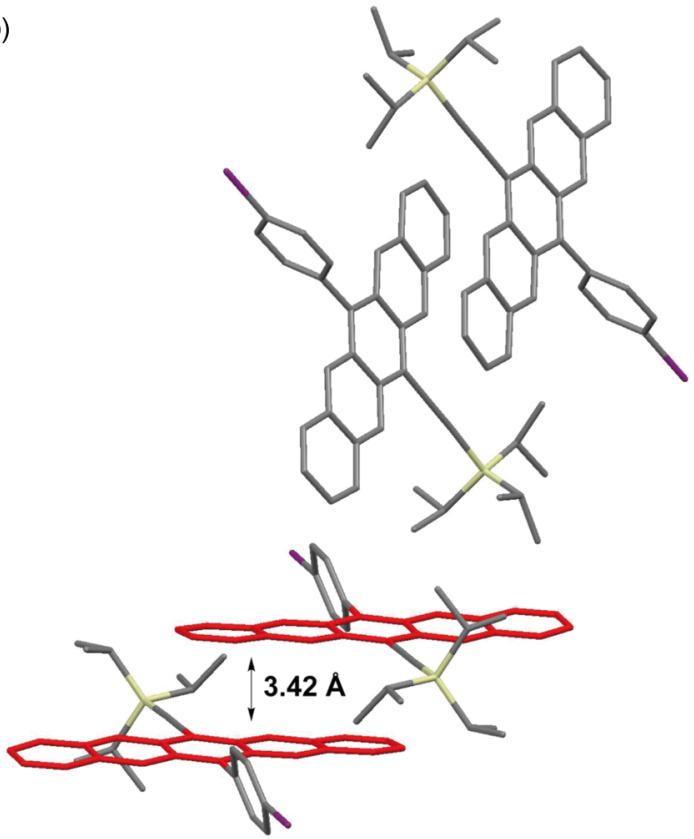

Figure 9: X-ray crystallographic analysis of $\mathbf{3 g}$ showing a) molecular structure and b) packing motif; ORTEP drawn at $50 \%$ probability level.

a)

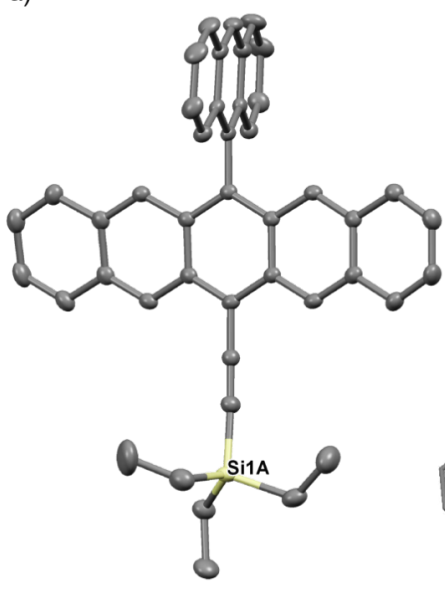

b)

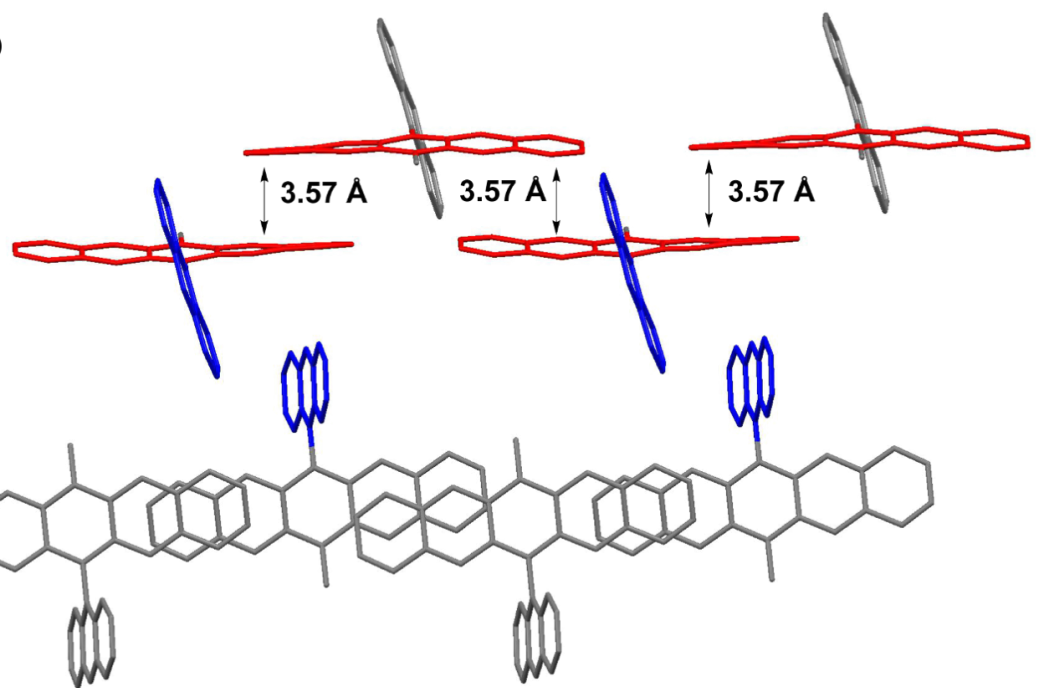

Figure 10: X-ray crystallographic analysis of $3 \mathrm{~h}$ showing a) molecular structure and b) packing motif (triethylsilyl groups omitted for clarity); ORTEP drawn at $50 \%$ probability level.

tached to the pentacene framework is nearly perpendicular to the pentacene core with an angle of $\sim 81^{\circ}$, while the torsion angle between the two rings of the biphenyl unit is $32^{\circ}$. The biphenyl substituent is slightly bent from linearity with an angle of $\sim 6^{\circ}$ (as estimated from the three atoms designated with an asterisk *). Biphenyl-substituted pentacene $\mathbf{3} \mathbf{i}$ arranges in a $1 \mathrm{D}$ slipped stack motif along the crystallographic $c$-axis, with $\pi$-stacking distances of $3.28 \AA$ and $3.35 \AA$.

Pentacene derivative $\mathbf{3} \mathbf{j}$ crystallizes in the space group $P$-1 with two molecules in the unit cell (Figure 12). Interestingly, the pentacene core and the naphthyl group are nearly coplanar $\left(4^{\circ}\right)$, 
a)

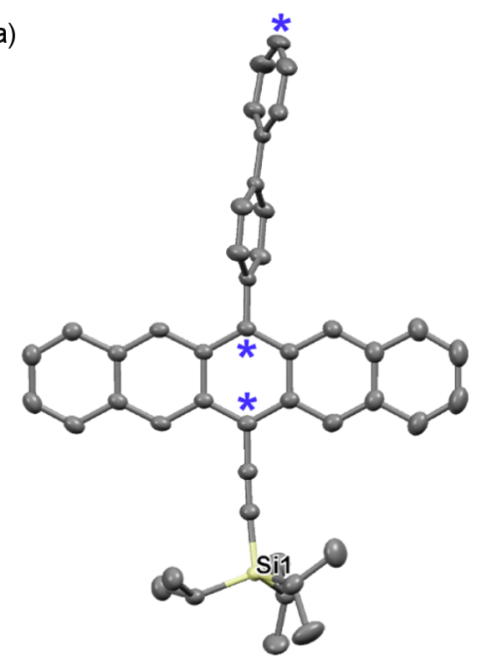

b)

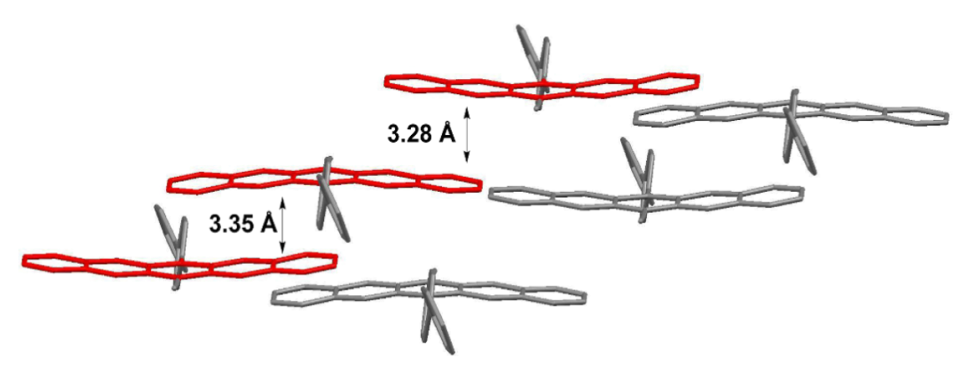

Figure 11: X-ray crystallographic analysis of 3i showing a) molecular structure and b) packing motif (triisopropylsilyl groups omitted for clarity); ORTEP drawn at $50 \%$ probability level.

a)

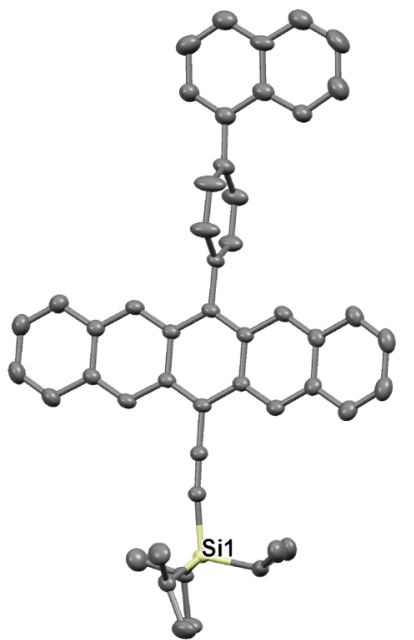

b)

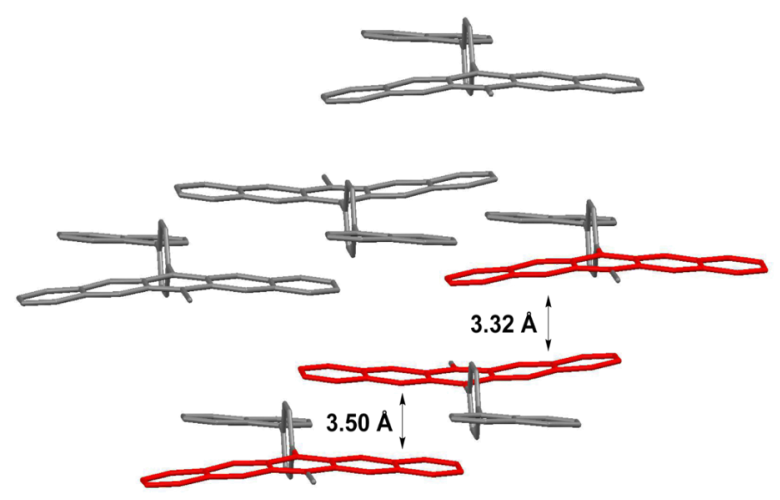

Figure 12: X-ray crystallographic analysis of 3j showing a) molecular structure and b) packing motif (triisopropylsilyl groups omitted for clarity); ORTEP drawn at $50 \%$ probability level.

while the intervening benzene ring is nearly perpendicular to both the pentacene skeleton $\left(\sim 90^{\circ}\right)$ and the naphthyl group $\left(\sim 86^{\circ}\right)$. Compound $3 \mathbf{j}$ arranges in a $1 \mathrm{D}$ slipped stack arrangement along the crystallographic $b$-axis with two different interplanar distances of $\sim 3.50 \AA$ and $3.32 \AA$.

\section{Conclusion}

In summary, a library of unsymmetrically substituted pentacenes has been synthesized by a straightforward procedure that requires only one purification step. Optical spectroscopy and cyclic voltammetry reveal that electronic communication between the pentacene core and the different substituents is limited, as a result of the orthogonal orientation of the pentacene backbone and the pendent aryl moieties. Thus, these results show that the nature of the substituent does not change the electronic properties of the pentacene skeleton itself. Aryl-substitution pattern does however, have a considerable effect on solid-state arrangement of the molecules, and X-ray crystallographic analysis afforded insight on the packing arrangements of the synthesized pentacenes. In spite of the large number of crystallographic analyses that have been examined here, general trends are difficult to establish based on, for example, either the number of $\pi-\pi$ and $\mathrm{CH}-\pi$ interactions or the size of the aromatic group appended to the pentacene core. It 
does seem, however, that anthracenyl substitution (in $\mathbf{3 c}$ and 3h) affords the highest degree of $\pi$-stacking amongst the derivatives examined.

\section{Supporting Information}

\section{Supporting Information File 1}

Experimental procedures and characterization data for all new compounds. Copies of ${ }^{1} \mathrm{H}$ and ${ }^{13} \mathrm{C} N M R, U V-v i s$, and emission spectra; CV, DSC, and TGA scans.

[http://www.beilstein-journals.org/bjoc/content/ supplementary/1860-5397-10-178-S1.pdf]

\section{Acknowledgements}

The authors acknowledge funding for this work from the Energie Campus Nürnberg (EnCN), "Solar Technologies go Hybrid" (an initiative of the Bavarian State Ministry of Science, Research and Art), and the Deutsche Forschungsgemeinschaft (DFG) through the Cluster of Excellence "Engineering of Advanced Materials". We thank Dr. Michael J. Ferguson for the $\mathrm{X}$-ray crystallographic analysis of ketone $\mathbf{4 b}$.

\section{References}

1. Figueira-Duarte, T. M.; Müllen, K. Chem. Rev. 2011, 111, 7260-7314. doi:10.1021/cr100428a

2. Hains, A. W.; Liang, Z.; Woodhouse, M. A.; Gregg, B. A. Chem. Rev. 2010, 110, 6689-6735. doi:10.1021/cr9002984

3. Lucas, B.; Trigaud, T.; Videlot-Ackermann, C. Polym. Int. 2012, 61, 374-389. doi:10.1002/pi.3213

4. Beaujuge, P. M.; Fréchet, J. M. J. J. Am. Chem. Soc. 2011, 133, 20009-20029. doi:10.1021/ja2073643

5. Cheng, Y.-J.; Yang, S.-H.; Hsu, C.-S. Chem. Rev. 2009, 109, 5868-5923. doi:10.1021/cr900182s

6. Mártin, N.; Sánchez, L.; Herranz, M. Á.; Illescas, B.; Guldi, D. M. Acc. Chem. Res. 2007, 40, 1015-1024. doi:10.1021/ar700026t

7. Dang, M. T.; Hirsch, L.; Wantz, G.; Wuest, J. D. Chem. Rev. 2013, 113, 3734-3765. doi:10.1021/cr300005u

8. Arias, A. C.; MacKenzie, J. D.; McCulloch, I.; Rivnay, J.; Salleo, A. Chem. Rev. 2010, 110, 3-24. doi:10.1021/cr900150b

9. Hains, A. W.; Liang, Z.; Woodhouse, M. A.; Gregg, B. A. Chem. Rev. 2010, 110, 6689-6735. doi:10.1021/cr9002984

10. Mei, J.; Diao, Y.; Appleton, A. L.; Fang, L.; Bao, Z. J. Am. Chem. Soc. 2013, 135, 6724-6746. doi:10.1021/ja400881n

11. Lehnherr, D.; Tykwinski, R. R. Materials 2010, 3, 2772-2800. doi: $10.3390 / \mathrm{ma} 3042772$

12. Lehnherr, D.; Tykwinski, R. R. Aust. J. Chem. 2011, 64, 919-929. doi:10.1071/CH11169

13. Anthony, J. E. Chem. Rev. 2006, 106, 5028-5048. doi:10.1021/cr050966z

14. Anthony, J. E. Angew. Chem., Int. Ed. 2008, 47, 452-483. doi:10.1002/anie.200604045

15. Bendikov, M.; Wudl, F.; Perepichka, D. F. Chem. Rev. 2004, 104, 4891-4946. doi:10.1021/cr030666m
16. Anthony, J. E.; Brooks, J. S.; Eaton, D. L.; Parkin, S. R. J. Am. Chem. Soc. 2001, 123, 9482-9483. doi:10.1021/ja0162459

17. Lehnherr, D.; Murray, A. H.; McDonald, R.; Tykwinski, R. R. Angew. Chem., Int. Ed. 2010, 49, 6190-6194. doi:10.1002/anie.201000555

18. Lehnherr, D.; Murray, A. H.; McDonald, R.; Ferguson, M. J.; Tykwinski, R. R. Chem.-Eur. J. 2009, 15, 12580-12584. doi:10.1002/chem.200902179

19. Lehnherr, D.; Gao, J.; Hegmann, F. A.; Tykwinski, R. R. J. Org. Chem. 2009, 74, 5017-5024. doi:10.1021/jo9007089

20. Lehnherr, D.; McDonald, R.; Ferguson, M. J.; Tykwinski, R. R. Tetrahedron 2008, 64, 11449-11461. doi:10.1016/j.tet.2008.09.041

21. Lehnherr, D.; Gao, J.; Hegmann, F. A.; Tykwinski, R. R. Org. Lett. 2008, 10, 4779-4782. doi:10.1021/ol801886h

22. Lehnherr, D.; Tykwinski, R. R. Org. Lett. 2007, 9, 4583-4586. doi:10.1021/ol702094d

23. Kuninobu, Y.; Seiki, T.; Kanamaru, S.; Nishina, Y.; Takai, K. Org. Lett. 2010, 12, 5287-5289. doi:10.1021/ol102349r

24. Li, Y.; Wu, Y.; Liu, P.; Prostran, Z.; Gardner, S.; Ong, B. S. Chem. Mater. 2007, 19, 418-423. doi:10.1021/cm062378n

25. Lee, S. H.; Kim, S. H.; Choo, D. J.; Jang, J. Org. Electron. 2010, 11, 1268-1272. doi:10.1016/j.orgel.2010.03.018

26. Wang, C.; Dong, H.; Hu, W.; Liu, Y.; Zhu, D. Chem. Rev. 2012, 112, 2208-2267. doi:10.1021/cr100380z

27. Zade, S. S.; Bendikov, M. J. Phys. Org. Chem. 2012, 25, 452-461. doi:10.1002/poc.1941

28. Biermann, D.; Schmidt, W. J. Am. Chem. Soc. 1980, 102, 3163-3173. doi:10.1021/ja00529a046

29. Bénard, C. P.; Geng, Z.; Heuft, M. A.; VanCrey, K.; Fallis, A. G. J. Org. Chem. 2007, 72, 7229-7236. doi:10.1021/jo0709807

30. Anthony, J. E.; Eaton, D. L.; Parkin, S. R. Org. Lett. 2002, 4, 15-18. doi:10.1021/ol0167356

31. Etschel, S. H.; Waterloo, A. R.; Margraf, J. T.; Amin, A. Y.; Hampel, F.; Jäger, C. M.; Clark, T.; Halik, M.; Tykwinski, R. R. Chem. Commun. 2013, 49, 6725-6727. doi:10.1039/c3cc43270j

32. Zhang, J.; Pawle, R. H.; Haas, T. E.; Thomas, S. W., III. Chem.-Eur. J. 2014, 20, 5880-5884. doi:10.1002/chem.201402003

33. Kim, Y.-E.; Park, J.-W. Mol. Cryst. Liq. Cryst. 2006, 444, 137-143. doi:10.1080/15421400500365318

34. Zhang, X.; Jiang, X.; Luo, J.; Chi, C.; Chen, H.; Wu, J. Chem.-Eur. J. 2010, 16, 464-468. doi:10.1002/chem.200902675

35. Lehnherr, D.; McDonald, R.; Tykwinski, R. R. Org. Lett. 2008, 10, 4163-4166. doi:10.1021/ol801464k

36. Waterloo, A. R.; Kunakom, S.; Hampel, F.; Tykwinski, R. R. Macromol. Chem. Phys. 2012, 213, 1020-1032. doi:10.1002/macp.201100622

37. Boudebous, A.; Constable, E. C.; Housecroft, C. E.; Neuburger, M.; Schaffner, S. Acta Crystallogr., Sect. C 2006, 62, o243-0245. doi:10.1107/S0108270106008262

38. Vets, N.; Smet, M.; Dehaen, W. Synlett 2005, 217-222. doi:10.1055/s-2004-836055

39. Maulding, D. R.; Roberts, B. G. J. Org. Chem. 1969, 34, 1734-1736. doi:10.1021/jo01258a045

40. Platt, A. D.; Day, J.; Subramanian, S.; Anthony, J. E.; Ostroverkhova, O. J. Phys. Chem. C 2009, 113, 14006-14014. doi:10.1021/jp904021p

41. Ostroverkhova, O.; Shcherbyna, S.; Cooke, D. G.; Egerton, R. F.; Hegmann, F. A.; Tykwinski, R. R.; Parkin, S. R.; Anthony, J. E. J. Appl. Phys. 2005, 98, 033701. doi:10.1063/1.1949711 
42. Lee, K. O.; Gan, T. T. Chem. Phys. Lett. 1977, 51, 120-124. doi:10.1016/0009-2614(77)85368-2

43. Mattheus, C. C.; Dros, A. B.; Baas, J.; Oostergetel, G. T.; Meetsma, A.; de Boer, J. L.; Palstra, T. T. M. Synth. Met. 2003, 138, 475-481. doi:10.1016/S0379-6779(02)00467-8

44. Mattheus, C. C.; Dros, A. B.; Baas, J.; Meetsma, A.; de Boer, J. L.; Palstra, T. T. M. Acta Crystallogr., Sect. C 2001, 57, 939-941. doi:10.1107/S010827010100703X

45. Siegrist, T.; Kloc, C.; Schön, J. H.; Batlogg, B.; Haddon, R. C.; Berg, S.; Thomas, G. A. Angew. Chem., Int. Ed. 2001, 40, 1732-1736. doi:10.1002/1521-3773(20010504)40:9<1732::AID-ANIE17320>3.0.CO ;2-7

46. Mattheus, C. C.; de Wijs, G. A.; de Groot, R. A.; Palstra, T. T. M. J. Am. Chem. Soc. 2003, 125, 6323-6330. doi:10.1021/ja0211499

47. Campbell, R. B.; Robertson, J. M.; Trotter, J. Acta Crystallogr. 1962, 15, 289-290. doi:10.1107/S0365110X62000699

48. Anthony, J. E.; Subramanian, S.; Parkin, S. R.; Park, S. K.; Jackson, T. N. J. Mater. Chem. 2009, 19, 7984-7989. doi:10.1039/b911560a

49. Kim, D. H.; Lee, D. Y.; Lee, H. S.; Lee, W. H.; Kim, Y. H.; Han, J. I.; Cho, K. Adv. Mater. 2007, 19, 678-682. doi:10.1002/adma.200601259 50. Lim, Y.-F.; Shu, Y.; Parkin, S. R.; Anthony, J. E.; Malliaras, G. G. J. Mater. Chem. 2009, 19, 3049-3056. doi:10.1039/b818693f

\section{License and Terms}

This is an Open Access article under the terms of the Creative Commons Attribution License (http://creativecommons.org/licenses/by/2.0), which permits unrestricted use, distribution, and reproduction in any medium, provided the original work is properly cited.

The license is subject to the Beilstein Journal of Organic Chemistry terms and conditions:

(http://www.beilstein-journals.org/bjoc)

The definitive version of this article is the electronic one which can be found at:

$\underline{\text { doi: } 10.3762 / \text { bjoc. } 10.178}$ 